of August 14th the eyelids were very puffy. There was no albumen in the urine. On August 18th the spots were scaling, but still hard generally; in a few places a little serum escaped, and in others pus, evidently due to infection by scratching with his nails.

By August 20 th the colour of the rash had faded considerably, but the papules were still hard and shotty. The general health of the patient was better; he was anxious to get back to his home as his wife had been confined whilst he was in hospital; he left for Canton this day.

I heard from his doctor that after a few days' rest at home he was able to return to his work, and as he has not seen him since he presumes all is well.

This case illustrates the sudden onset of symptoms without any warning. It shows also the long duration of the rash after all drugs had been stopped, the delirium that accompanied the poisoning, the weakness of the pulse and danger to life if not recognized at once and stopped, as illustrated in Dr. Wood's cases in Philadelphia. The case shows also the possibility of mistaking the hard shotty papules for variola in its later stage, and also shows the inadvisability of anyone out of reach of skilled medical advice using boric acid rectal injections for dysentery. In this case no boric acid was given by the mouth, and it illustrates the rapidity and ease with which boric acid solution is absorbed by the bowel.

\section{A CASE OF VEGETABLE GASTROLITH.}

$$
B Y
$$

PEVERELL S. HICHENS, M.D.Oxon., F.R.C.P.LoNid, HONORARY PHYSICIAN, NORTHAMPTON GENERAL HOSPITAL;

AND

N. B. ODGERS, M.Ch.Oxon., F.R.C.S.Exg. HONORARY ASSISTANT SCRGEON, NORTHAMPTON GENERAL HOSPITAL.

THe patient, a young woman of 24 , made her appearance at the out-patient department of the Northampton General Hospital in May, 1911, complaining of pain and a sinking feeling in the stomach and vomiting for the past month. No blood had been vomited. She gave no history of any peculiar habits in her eating.

On examination she was found to have a large tumour running across the epigastrium. It was of a peculiar character, being smooth, hard, and rounded, both above and below. 'The lower edge reached to the umbilicus. The tumour filled up the whole space between the angle of the ribs. It was freely movable on respiration, and on deep inspiration the examining hand could be slipped above the rounded upper limit of the tumour and hold it down.

Many speculations were made as to what the mass could be. Amongst them an anomalous floating kidney was suggested, Amongst them an anomalous floating kidney was suggested, but, on the whole, the most likely diagnosis seemed to be a
floating liver, causing gastric symptoms from the displacement

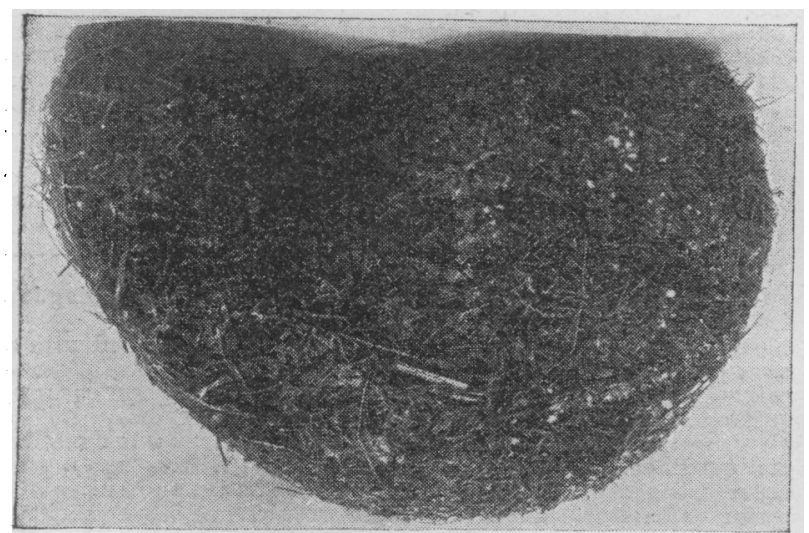

Fig. 1.-Mass of cocoanut fibre removed from stomach.

of the stomach. Against this diagnosis was the fact that there was apparently a fingerbreadth of liver dullness at the fiftl right rib, with resonance above and below it.

An exploratory operation was considered, but it was postponed, and the patient recovered entirely from her srmptoms with rest in bed in the hospital and a light diet, the tumour, however, remaining as before.

Acting on the supposition of the tumour being a floating liver, she was given a suitable abdominal belt before leaving the hospital on June 24th.

Nothing more was heard of the patient till early in August, when Dr.A. W. Moore, her medical attendant at Stony Stratford, wrote to tell us that the most startling developments hat taken place. She had been seized again with very acute pain in the ablomen, with rigidity, distension, a rapid pulse, and constant vomiting. An enema was given, and two masses, like pieces of a doormat, came away, one the size of a turkey's egs and one the size of a pigeon's egg. It then transpired, on a cross-examination of the patient, that she had been in the habit of eating wood and the fibre on the outside of cocoanuts.

Four months ago she went to a fair and secured a cocoanut at a cocoanut-shy, and ate, not only the interior, but the fibre fiom the outside. Dr. Moore considered that the acute attack of the outside. Dr. Moore considered that the acute attack of pain was due to the passage of the two masses of fibre through the prlorus and along the small intestine, accompanied by the passage of the fibre, he and Dr. Bull, who had also seen her. passage of the fibre, he and Dr. Bull, who had also seen her,
had come to the conclusion that the tumour was connected

with the stomach.

The patient was readmitted into the hospital, and was operated on by Mr. Odgers. The stomach was opened by : longitudinal incision, and a large tumour, consisting entirely, apparently, of matted cocoanut fibre, was removed from it. The tumour completely filled the stomach, and formed an exact cast of it. It is shown in the accompanying illustration. The weight of the tumour was $1 \mathrm{lb} .2 \frac{3}{4} \mathrm{oz}$. Mixed with the tumour was a good deal of fat and gastric juice. It is interesting to note that the walls of the stomach seemed quite healthy and uninflamed, and not at all irritated by their embarrassing inmate. The patient made an uninterrupted recover after the operation, and has so far remained well since.

On thinking over this curious case, the most extraordinary thing about it was the power that the stomach retained of digesting food quite well while it was entirely filled with this great tumour of cocoanut fibre. When the patient made her first stay in the hospital she was up anc abcut, and digesting perfectly well an ordinary mixed diet for three weeks before she left. This fact, combined with the absence of all history of her peculiar dietetic liabits, seemed to conclusively negative the diagnosis of a stomach tumour which was entertained, only to be set aside.

A reference, however, to the subjoined literature shows that the same anomaly has been observed before. Whilc masses of hair in the stomach have been found not infrequently-Dr. Butter'worth ${ }^{1}$ collected 42 cases from the literature in 1909-vegetable "gastroliths" appear to be very rare.

In 1854 Dr. Quain ${ }^{2}$ reported a case very similar to our's for Dr. Bucknill to the Pathological Society:

This patient was a young man, aged 22, an epileptic. For some time he had been in the habit of eating gravel, rags, and dirt, and had slight attacks of diarrhoea from time to time, "by which he got rid of them easily." No epigastric tumour was ever observed, the patient dying of acute peritonitis. At z po: $t$ mortem examination there was a perforation of the lesser mortem examination there was a perforation of the lesser curvature of the stomach the size of a shilling, and within the
stomach a mass, $4 \mathrm{lb}$. in weight, composed almost entirely of cocoanut fibre and bits of string. "It is very remarkable that he appeared to be in his normal good health, took and digester all his meals, and was well nourished, with all this stuff in his paunch.'

In 1861 Dr. Capelle ${ }^{3}$ reported the case of a woman in whom a diagnosis of gastric carcinoma had been made. This she discredited by vomiting a large foreign body composed of vegetable débris. In 1881 Dr. Langenbach removed by operation a gastrolith consisting of starch, fat, and amorphous material. This is figured in his paper, and is a cast of the stomach like our own specimen. This patient has been in the habit of taking " Nuss blätter-thee." In 1888 Dr. Kookver ${ }^{5}$ described a similar specimen found post mortem, and in $1896 \mathrm{Dr}$. Schreiber ${ }^{6}$ removed by operation a "phytobezoar" composed of Schwarzwiirzel roots. The plant is said to be a popular remedy in Germany.

In the ruminants concretions are commonly found in the first or second stomachs. These are either so-called "fodder balls" composed of vegetable fibre, or hair balls. Similarly in the antelope and camel occur "bezoar stones," which are supposed to be famous antidotes.

Dr. Butterworth, in his paper on " hair-balls," finds, from the cases he has collected, that epigastric pain is the only constant symptom; vomiting occurs at some time in most cases; haematemesis is rare. Dyspepsia and an abdominal tumour are the two carliest symptoms as a rule. With regard to diagnosis, out of 33 cases, in 5 only was the condition correctly determined. In others the following were thought of: Cancer of the stomach, displaced spleen, floating kidney, faecal impaction in the transverse colon, and omental tumour. In Dr. Still's case ${ }^{7}$ the conditions discussed were enlarged spleen and lymphosarcoma or a tuberculous infiltration. Of Dr. Butterworth's 33 cases, 
16 recovered after an operation, 1 died; of cases not operated upon, 6 died of peritonitis and 10 of inanition.

REFERENCES.
${ }^{1}$ Butterworth: Toum. Amer. Med. Assoc, Chicago, 1909, vol. liii, p. 617. 2 Quain: Trans. Path. Soc., 1854, vol. v, p. 145. 3 Capelle : Journ. de Méd. de Bruxelles, February, 1861, p. 147. ${ }^{4}$ Langenbach: lerhand. der deutsch. Gezell für Chirurgie, 1881, Ninth Congress, 1. 54. "5 Kookver: Zeit. fïr klin. Med., 1888, xiv, 1. 203. 6 Schreiber, Mitt. a. d. Grenzgeb. d. Med. a. d. Chirurgie, 1896, 1, p. 729. ${ }^{7}$ Still:
Proc. Loy. Soc. Med., C'linical Section, 1907-8, p. 212.

\section{Atemoranda :}

\section{MEDICAL, SURGICAL, OBSTETRICAL.}

\section{A POSITION OF THE THORAX FAYOURING} APICAL DIAGNOSIS.

I HAVE on several occasions found that patients placed in the attitude shown in the photograph-a kind of "stoop-down-to-lace-your-boots" posture - give accentuated auscultation and percussion sounds in early tuberculous

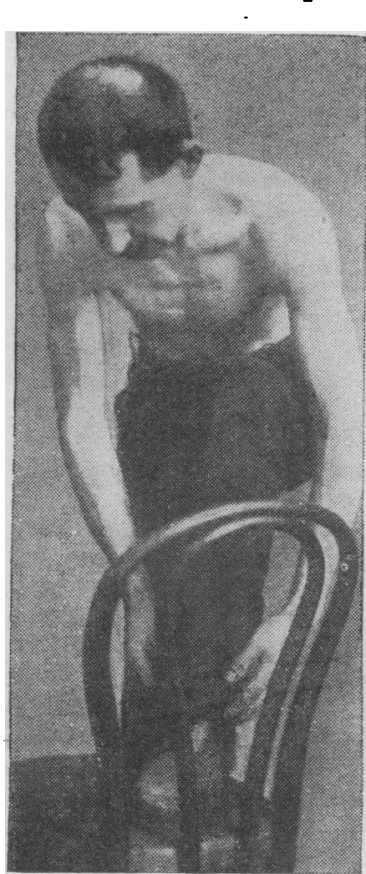
mischiof at the pulmonary apices The assumption of this position allows the soft parts of the supraclavicular and infraclavicular regionsthe latter a space between the deltoid and the clavicular portion of the pectoralis major muscles-to "drop in." The raised thigh, causing abdominal pressure, will push the diaphragm and lungs upwards, hence favouring an elevation of their apical portions. The bending forwards of the head - practically by its own weight-renders the depressor muscles lax, thereby causing "the roof" of the clavicular regions--platysma and cervical fascia - to become less tense the latter being " pulled down" nearer the pulmonary apices by its deeper attach ments. This posture is also serviceable in middle-lobe dia gnesis, since the " auscultation triangle" - that is, the space between trapezius, latissimus dorsi, and rhomboideus major muscles-is widened, due to the pulling outwards of the inferior angle of the scapula whereby the muscular thickness that usually abounds in this neighbourhood is considerably lessened.

Barton-on-Humber.

Charles A. Beck。

\section{ANAESTHESIA FOR SUBMUCOUS RESECTION OF} THE SEPTUM.

WITH regard to Mr. Seymour Jones's note in the JournaL of February 24th, p. 421, advising the use of cocaine and adrenalin by submucous injection to procure anaesthesia in septal resection, may I say that I tried this method (substituting eucaine for cocaine) and gave it up years ago ? The addition or use of a general anaesthetic in this opera. tion is not necessary, certainly not in more than 2 per cent of the cases. One can procure in five minutes absolute and safe anaesthesia lasting an hour by Freer's simple method: Dip small cotton-tips in 1 in 4,000 or 1 in 5,000 adrenalin solution, pick up on these a few crystals of pure cocaine hydrochloride and rub on the mucous membrane. Have the cocaine weighed in 1-grain packets-more than 2 grains are seldom necessary. Only once in about 100 cases of septal resection have I required a general anaesthetic, and that was in a lad who fainted whenever a nasal speculum was introduced into his nostril. Anaesthesia by submucous injection is rarely necessary for any intranasal operation. What Dr. Walker Wood says in the Jovrnal (vol. ii, 1911, p. 1059) on this matter I can quite endorse.

Hamilton.
TREATMENT OF PRURITUS VULVAE AND ANI.

Dr. GIbBons, in his very interesting lecture on pruritus vulvae and its treatment, makes no mention of urotropin, a drug which $I$ have found of extraordinary value in these conditions. The notes of the following two cases will demonstrate its value in these very unpleasant and distressing conditions :

1. A lady, for whom I removed a broad ligament cyst, developed a most severe pruritus of the vulva, the irritation being extreme-so much so, that she scratched the parts until they bled. Careful examination of the vulva and vagina was made, but there was nothing to suggest a local cause. The urine was examined, and no abnormal product found. Various remedies were tried, but with little avail. I then prescribed urotropin, gr. 10 three times a day in water. Within a few days the itching entirely ceased, and the accompanying dermatitis disappeared. She has had no recurrence since this attack three years ago.

2. A man consulted me about intolerable itching of the anus and scrotum. He had been treated by several doctors, and had had a host of remedies tried, but all to no good. I examined the rectum, faeces, and urine, but could find no clue to its origin. As the intolerable itching was preying on his mind and medicinal remedies had failed, I dissected up the skin around the anus, aftei Sir Charles Ball's method. This promptly gave him relief, but it only lasted for a short time. Some weeks after the operation he wrote me to say the itching was as bad as ever. I then prescribed $10 \mathrm{gr}$. of urotropin three times daily in water, and also directed him to smear: the parts with ung. metallorum. Almost at once the itching ceased, and has not returned up to the present-a period of two years.

Several other cases have had the same happy result, and, though I do not say this is a panacea for all cases, yet it is well worthy of a trial when careful examination of the parts has failed to reveal any definite cause. Newruas. C. E. Caypbell-Honsfald, M.B., Ch.B.Vict. Univ.

\section{MORTALITY AFTER OPERATIONS FOR APPENDICITIS.}

Thasks to the promptitude with which medical men have cases of appendicitis operated on, the mortality is very much less than it used to be. Looking over the last 281 cases operated on in the quiescent stage, I find that no death occurred from the operation. A case of sudden death took place three weeks afterwards, but this is fortunately a very exceptional occurrence at so late a stage.

The last 93 cases of appendicitis with abscess formation, which were all operated on promptly, recovered. One case which was not operated on until septic absorption had taken place to a considerable extent died. It is satisfactory to find that the number of cases of general peritonitis sent to be operated on has greatly diminished during the last three years, and when sent they are at a much earlier stage, and recovery, therefore, is much more certain. Where patients have passed the third day of their illness the mortality is very high"; when operated upon on the first or second day the mortality is frequently as low as 2 per cent.

This improvement is greatly helped by patients being brought to hospital or homes in the sitting-up posture, and also being operated on and nursed as nearly as possible in the Fowler position. - Saline rectal infusion has been a powerful aid in diminishing the mortality.

J. Crawford Renton, M.D., Surgeon, Western Infirmary, Glasgow.

THE late Sir Henry Trentham Butlin left estate valued at $£ 90,996$.

UNDER the will of the late Miss Helen Swindells of Birkdale, Lancashire, the following institutions receive bequests to the amount set against their names: The Cancer Research and Pathological Department of the University of Manchester £5,000, Manchester Royal Infirmary $£ 4,000$, St. Mary's Hospital and the Hospital for Consumption and Diseases of the Throat $£ 3,000$ each, the Children's Hospital, Pendlebury, the Northern Counties Hospital for Incurables, and the Devonshire Hospital, Devon, £2,000 each, and the Southport and Birkdale Nursing Society $£ 1,000$. 